\title{
JOURNEYING TO INDEPENDENCE AND AUTONOMY: TRANSITION NORMS AND EMPOWERING ADOLESCENTS WHO ARE DEAF AND HARD OF HEARING
}

\begin{abstract}
When discussing transitions of deaf and hard of hearing adolescents, we have to perceive them holistically, and to recognize the nature and complexity of the relationships between traditional transitions. Measures of 'successful' or 'unsuccessful' transitions, do not necessarily align with the traditional events-based and institutional transitions. We need to broaden our understandings of transitionary processes and desirable outcomes. Successful transition begins with trusting deaf and hard of hearing students to lead their own transition planning.

Autonomy of deaf adolescents is linked to better employment with more opportunities for advancement and higher income. Autonomous beliefs, capacities, and actions are associated with improved outcomes for students with disabilities. When we are discussing employment opportunities, it is evident that there has been a shift of the traditional parameters of the industrial society. The old traditional occupations are replaced by the necessity for individuals to adapt to new standards of work and changing labour market conditions, by for example, re-training or switching occupations. To support development of autonomy, environments must facilitate opportunities for the individual to take control over their own lives, to make choices and decisions freely.

When we discuss independence and autonomy, we must also relate it to new and uprising technologies. Technology can mean increased access, independence, and reliance of oneself. With high expectations from parents and teachers and using technology for meaningful education, these deaf and hard of hearing adolescents will be ready for college and careers.
\end{abstract}

Keywords: DEAF, ADOLESCENCE, AUTONOMY, INDEPENDENCE

\section{Introduction}

Transition is a complex and drawn-out process at the best of times, particularly so for disabled young people (Winn\&Hay, 2009). There are particular problems associated with making the transition to adulthood for young $d /$ Deaf people, ${ }^{1}$ who often miss information due to the absence of unproblematic

\footnotetext{
${ }^{1}$ It is a convention in the field of Deaf studies to capitalise the word 'Deaf' to represent the Deaf community or members of the Deaf community (Padden and Humphries, 1988).
} 
communication with family, peers, teachers and other professionals who traditionally provide support through this period (Gregory, Bishop\&Sheldon, 1995). This lack of incidental learning can have serious effects on young $d /$ Deaf people's ability to make informed decisions about their education and employment, and can delay their transition to adulthood and independence. Successful transition begins with trusting deaf and hard of hearing students to lead their own transition planning (Martin, Marshall, \& DePry, 2001).

The Deaf community in North Macedonia is a socio-linguistic group that has its own sign language, Macedonian Sign Language (MSL), and has its own culture, history, beliefs and traditions. Many young d/Deaf people go through identity transitions at some point in their lives, from deaf to Deaf.

\section{Historical overview of Transitions}

Transition is the link, or bridge, between the educational experience and eventual integration into the community for individuals with disabilities (Bryant, Bassett\&Webb, 2008). Historically, work opportunities for persons with disabilities have never been plentiful. Equal opportunity has never been universally practiced, and disability imposes further limitations on educational opportunity (Clark \& Kolstoe, 1995, p. 4).

Halpern (1994) expanded the concept of transition to go beyond employment. He called for the model to include dimensions of adult adjustment and community involvement. Harmon, Manlon and Beach (2019) also underscore the point that transition and success encompass more than postsecondary employment. They point out that working comprises only approximately onethird of a person's day. The remaining two-thirds involve adult living skills. Gerber and Reiff (1991) note that recent models of transition do extend beyond the concept of school-to-work transition and include school to postsecondary education and training and transition to independent community living.

More consideration should be given to the specific needs of $d /$ Deaf young people in transition planning, and the unique knowledge and experience of $d /$ Deaf professionals should be harnessed more effectively in creating a policy that affects young d/Deaf people.

\section{$d /$ Deaf transitions in the hearing world}

Ninety-five per cent of D/Deaf people are born into hearing families (Valentine\&Skelton, 2007). The first introduction that their parents have to D/ Deafness is usually as a result of medical professionals' definitions that their child is 'not developing in a typical manner'. In the case of D/Deaf people this usually means offering D/Deaf children hearing aid technologies (and cochlear implants) and training in oral methods of communication (lip-reading and speech). Hearing parents usually have little or no knowledge of Deaf culture and of the possibilities of using MSL as a method of communication in the family and signing based educational opportunities. As such, the limited opportu- 
nities that $\mathrm{D} /$ Deaf young people have to understand or communicate with hearing people mean that they often feel very isolated from the world around them, receive limited support and thus a poor start in terms of the acquisition of literacy and language (Gregory et al., 1995; Corker, 1996; Foster, 2003). Such experiences of hearing family life also mean that deaf young people have low expectations of opportunities in the wider world.

Moorhead (1995) characterizes D/Deaf people's experience of making the transition to adulthood in the hearing world as one of struggle and challenge. Most notably they struggle to understand the world around them, to access information to enable them to make their own informed choices, and to control their own lives in the face of the hearing people's stigma of deafness and the professionals and institutions that impose meanings on their experiences (Corker, 1996). As a result, mental health problems are prevalent amongst Deaf young people.

Family protectiveness, which is often seen as negative, can be very positive if it builds a young person's self-esteem and confidence and so supports school-to-work and housing transitions. Deaf persons who lacked such domestic support and had to make their own way in the world might be regarded as more independent and therefore as having made a positive transition to adulthood, yet have experienced negative outcomes, such as unemployment, because they have lacked support at crucial moments. In this way, dependence and independence are not mutually exclusive or contradictory states in which a young person moves from one to the other in a one-off process (Jones \& Wallace, 1992). Rather, dependency in one context may support independence in another context, and vice versa some forms of independence, if premature or unsuccessful, might reproduce other forms of dependency. It is therefore crucial to look at transitions in a holistic sense, recognizing relationships between different transitional elements, and that people might be simultaneously dependent in one aspect of their lives yet independent in another. Moreover, although simple definitions of independence and dependence are being replaced by more complex analyses of different transitions to adulthood, individual autonomy is still assumed to be the outcome.

Measures of 'successful' or 'failed' transitions, do not necessarily accord with the traditional events-based and institutional transitions. Nor do they necessarily occur within a fixed age range. Rather, D/Deaf young people's emphasis on the importance of MSL and making the transition to an independent identity in the Deaf, instead of (or as well as) the hearing world, demonstrates the need for social scientists to broaden our understandings of transitionary processes and desirable outcomes away from 'normal' measures of desirable pathways. This is perhaps best achieved through grounded research with young people themselves, that acknowledges their agency in defining and managing their own life transitions. 


\section{Transition towards employability}

Successfully obtaining employment is a pivotal developmental milestone for many young adults, yet for some, it is beyond reach. Despite advances in accessibility legislation and academic attainment, deaf young adults in North Macedonia continue to face underemployment and underpayment. One has to ponder about the role of autonomy in the developmental process for deaf adolescents as they navigate the transition from adolescence to early adulthood and enter the workforce. The findings indicate that autonomy plays a significant role in the transition towards sustainable employment for deaf young adults. Parental expectations emerged as important antecedents of autonomy development for deaf adolescents, contributing both to autonomous motivations and independent functioning. Deaf adolescents' autonomy is linked to employment opportunities with greater opportunities for advancement and higher income, and thus offers the field a potential avenue for strengthening pathways towards sustainable employment for deaf individuals.

Despite promising high school completion rates and increasing rates of postsecondary enrolment and training among young adults (Erickson, Gildengers\&Butters, 2013), deaf individuals continue to be underpaid and underemployed compared with hearing peers over the course of their lives. Clearly, there are additional factors that contribute to successfully obtaining sustainable employment, beyond education and training. The transition to the workplace requires navigating multiple contexts, including home and school, and each of these contexts may have differing levels of salience for deaf individuals as they move from adolescence to early adulthood.

One constant that holds throughout the navigation of multiple contexts throughout the transition process towards employment settings is the presence of the individual's sense of self. Individual agency is a key factor that facilitates positive postsecondary outcomes, as explored through a variety of theoretical lenses such as resilience and self-determination (Wehmeyer, 1995). Youth with higher levels of individual agency are more likely to engage in actions that contribute towards achieving their goals. For example, students with disabilities who actively engage in their own transition planning are more likely to accomplish personally salient goals during high school and beyond.

\section{Independence}

Traditionally, young people's transitions from a state of dependent childhood to an independent adult identity have been measured in terms of a developmental stage model. However, it is increasingly being recognised that young people are not a universal category and that their transitions need to be understood within the diverse context of peers, family, and communities.

The key markers of adulthood have commonly been regarded as: leaving full-time education and entering the labour market; moving out of the parental home to establish an independent household; and marriage/co-habita- 
tion and parenthood (Morrow\&Richards, 1996). Coles (1997) has summarized these as the school-to-work transition, housing transition, and domestic transition.

\section{Autonomy}

Autonomy of deaf adolescents is linked to better employment with more opportunities for advancement and higher income. Autonomous beliefs, capacities, and actions are associated with improved outcomes for students with disabilities (Algozzine, Browder, Karyonen, Test\&Wood 2001; Chambers, Rabren\&Dunn, 2007). When we are discussing employment opportunities, it is evident that there has been a shift of the traditional parameters of the industrial society. The old traditional occupations are replaced by the necessity for individuals to adapt to new standards of work and changing labour market conditions, by for example, re-training or switching occupations. To support development of autonomy, environments must facilitate opportunities for the individual to take control over their own lives, to make choices and decisions freely (Wehmeyer et al. 2011).

Wehmeyer's functional self-determination theory is often utilized in research with individuals with disabilities to examine how such groups exercise individual agency to achieve important life outcomes including overall wellbeing and enhanced quality of life (Algozzine et al. 2001; Wehmeyer, 2007). Wehmeyer's theory of self-determination focuses less on internal psychological processes but rather on the skills, actions, and behaviours that render an individual self-determined (Wehmeyer\&Garner, 2003). Self-determination, as defined in Wehmeyer (1995), is the process by which individuals achieve their desired level of personal control within domains that they perceive to be important. This functional model of self-determination identifies four essential actions that characterize self-determined behaviour, which include: (a) acting in an autonomous manner; (b) self-regulation of behaviour; (c) responses to life events in psychologically empowering ways; and (d) acting in a manner that is self-realizing (2003; 2006). Autonomy, specifically, is conceptualized as cognitions or behaviours that are self-directed, initiated according to personal interests, and free from external influence (Wehmeyer 1995). Autonomy is an important outcome of the individuation process in which people behave in ways that are in accordance with their own preferences, and most importantly, free from excessive external influence.

However, in order to support autonomy development, environments must truly facilitate opportunities for the individual to exert control over their own lives, to make choices and decisions freely, as supported by the personenvironment interaction theory. Opportunities to exert autonomy are stronger contributors to self-determination, development than traditionally modelled personal characteristics such as IQ. 
Clearly, becoming self-determined requires both the capacity, and the opportunity, to do so. Despite the understanding that self-determination development requires opportunity, real-world opportunities to exercise selfdetermined behaviours are frequently limited for students with disabilities. Students with disabilities face contextual challenges including reduced access to participation in extracurricular activities, difficulty gathering the needed information for decision making, and unhelpful feedback regarding their strengths and limitations, which may result in an external locus of control which weakens their sense of volition and sense of career maturity (Biller 1985). Indeed, students with disabilities who live or work in more restrictive environments, or perceive barriers in their environments, exhibit lower levels of self-determination (Wehmeyer\&Garner, 2003), are less confident in leading their transition process and less likely to act on their career goals. Autonomy development is thus a critical domain to examine, particularly when considering the transition of deaf students from secondary into post-secondary settings.

For many, the earliest opportunities to develop self-determination take place in the home and family context. An often-studied antecedent of autonomy development is parental beliefs, attitudes, and practices. Parental beliefs and practices can foster environmental conditions in which their child can strengthen their sense of agency and volition. Youth with disabilities whose parents hold optimistic expectations about their abilities and potentials are more likely to exhibit independent behaviours during high school, such as assuming household responsibilities, earning higher grades, joining extracurricular activities, engaging positively in the classroom (Newman 2004), and leading their own transition planning meetings. Parent expectations about their child's future potential play a significant role in the development of their child's individual agency, creating conditions for the formation of self-determination (Rodriguez\&Cavendish, 2013) and autonomy (Doren, Gau\&Lindstrom, 2012; Soenens\&Vansteenkiste, 2005). In the general population, parental expectations of their child's future independence appear to be strongly linked with autonomy-supportive practices, behaviours that encourage youth to make choices, decisions, and engage in problem solving independently (Wong, 2008). Beyond supporting autonomy development and autonomous behaviours in high school, parental expectations also contribute to increased academic achievement. When parents hold low expectations about their child's potential, as found in parents of deaf youth (Michael, Cinamon\&Most, 2015), questions arise as to whether this results in reduced conditions for autonomous development.

The previous findings largely reflect research conducted with general populations, or those with disabilities. The research base is less robust when considering how parental expectations interact with the development of deaf youth. It is well documented that deaf youth often encounter low expectations about their potential for success in home, or in school (Borders, Browder, Karyonen, Test\&Wood, 2018). The vast majority of deaf children have hearing par- 
ents (more than $95 \%$ ) and most of these parents have minimal knowledge, if any, about the experience of being deaf. This limited knowledge often results in communication difficulties between the parent and the child and low expectations about deaf people's potential. Deaf young adults across the world encounter low expectations of their future achievement, a result that has been replicated cross-culturally, despite varying levels of access and opportunity for deaf people in each country (Danermark, Antonson\&Lundstrom, 2009; Parasnis, Samar\&Mandke, 1996). Previous research has revealed that parental expectations of their deaf adolescents' future achievements are strong predictors of future outcomes, from independent living, postsecondary enrolment and completion, and employment (Cawthon, Caemmerer, Dickson, Ocuto, Ge\&Bond, 2015).

\section{Exercising Autonomy in the Transition to Employment}

Autonomous functioning is a developmental process; individuals with a well-developed sense of autonomy are likely to exercise and build upon that autonomy throughout multiple settings if opportunities are present. Additionally, autonomy is positively linked to enhanced social, academic, and vocationnal wellbeing. Socially, autonomous behaviours lead to self-determined friendships, prosocial behaviour (Gagné\&Deci, 2005) and feelings of social competence (Soenens\&Vansteenkiste, 2005). Autonomy is also linked to outcomes within educational environments. Higher autonomous orientations were associated with higher grades (Soenens\&Vansteenkiste, 2005) and the greater likelihood of taking a leadership role in transition planning meetings in high school (Sanford, Newman, Wagner, Cameto, Knokey\&Shaver, 2011). When considering postsecondary environments, autonomous motivations are also linked to increases in enrolment, engagement, and completion of postsecondary programs for students with disabilities (Simonsen\&Neubert, 2013).

Importantly, beyond educational environments, autonomous motivations have been linked to a wide range of employment processes and outcomes, indicating that the effect of autonomy holds constant through multiple contexts and developmental milestones. Adolescents and young adults with autonomous orientations are likely to engage in independent job-seeking behaviours (Soenens\&Vansteenkiste, 2005) and to be committed to having a job even when unemployed.

As previously mentioned, among students with disabilities, self-determination was found to predict early work experience, but did not have a direct effect on later work experience (Shogren, Wehmeyer, Palmer, Rifenbark\&Little 2015). Rather, these early work experiences predicted later work experiences. In general, employment experience during high school predicts competitive employment after the high school years for students with disabilities (Wehman, Sima, Ketchum et al., 2014).

Taking a closer look at specific employment processes offers a more accurate picture of early employment trajectories that may be most effective in 
sustaining employment over longer periods of time. Increased work experience, as measured by the number of jobs held by the student, predicts future employment for young adults with disabilities (Benz, Lindstrom\&Yovanoff, 2000), and specifically those with visual impairments (McDonnall\&Crudden, 2009; McDonnall, 2010). For deaf youth, there was a positive relationship between having employment for at least 12 months and their future employment (Rabren, Dunn\&Chambers, 2002). Taking an even closer look at the type of early work experience is even more enlightening, as emergent findings suggest that school-sponsored work experience has little to no impact on future employment, while those work experiences that were independently obtained did so (McDonnall, 2010. These independent actions clearly have a relationship with future employment outcomes, yet the pathways from autonomous orientations and actions to future employment outcomes for deaf individual remains to be explored.

\section{Technology}

Technology enables young deaf learners to take charge of their own learning and to succeed. When we discuss independence and autonomy, we must also relate it to new and uprising technologies. Technology can mean increased access, independence, and reliance of one-self. With high expectations from parents and teachers and using technology for meaningful education, these deaf and hard of hearing adolescents will be ready for college and careers. (Bricker, 2015). Devices and technology have enabled deaf students to experience more independence and educational success.

Access to instruction is key to students' success. Deaf and hard of hearing students who gain skills to become independent learners are better prepared to pursue higher-level education with confidence and to have independence in the work place environment (Anderson, 2014).

Technology benefits everyone, but perhaps especially deaf and hard of hearing students; it allows them direct access to the world around them and continued connection with others. Technology can mean increased access, independence, and self-reliance.

\section{References:}

Algozzine, B., Browder, D., Karvonen, M., Test, D. W., \& Wood, W. M. (2001). Effects of Interventions to Promote Self-Determination for Individuals With Disabilities. Review of Educational Research, 71(2), 219-277. https://doi.org/10.3102/00346543071002219

ANDERSON, K. (2014). Supporting success for children with hearing loss. Retrieved from: www.successforkidswith hearing loss.com 
BenZ, M. R., LindSTROM, L., \& YOVANOFF, P. (2000). Improving Graduation and Employment Outcomes of Students with Disabilities: Predictive Factors and Student Perspectives. Exceptional Children, 66(4), 509-529. https://doi.org/10.1177/001440290006600405

Borders, C.M., BOCK, S.J., GiESE, K., GARDiner-Walsh, S. AND PrOBST, K.M. (2018). Interventions for Students Who Are Deaf/Hard of Hearing, Obiakor, F.E. and Bakken, J.P. (Ed.) Viewpoints on Interventions for Learners with Disabilities (Advances in Special Education, Vol. 33), Emerald Publishing Limited, pp. 75-105. https://doi.org/10.1108/S0270-401320180000033005

BRICKER, V. (2015). iPads for Access, Independence, and Achievement. Odyssey : New Directions in Deaf Education, 16, 10-13.

Cawthon, S., Caemmerer, J., Dickson, D., Ocuto, O., Ge, J. \& Bond, M. (2015). Social Skills as a Predictor of Postsecondary Outcomes for Individuals Who Are Deaf, Applied Developmental Science, 19:1, 19-30, DOI: $10.1080 / 10888691.2014 .948157$.

Chambers, D., Rabren, K., \& DunN, C. (2009). A Comparison of Transition From High School to Adult Life of Students With and Without Disabilities. Career Development for Exceptional Individuals, 32(1), 42-52.

https:// doi.org/10.1177/0885728808323944

Clark, G.M. \& KOlstoe, O.P. (1995). Career Development and Transition Education for Adolescents with Disabilities. 2nd edition. Boston: Allyn and Bacon.

COLES, B. (1997), Welfare services for young people in Roche, J. and Tucker, S. (eds), Youth in Society: Contemporary Theory, Policy and Practice, London: Sage.

CORKER, M. (1996). Deaf transitions: Images and origins of Deaf Families, Deaf Communities and Deaf Identities. London: Jessica Kingsley Publishers.

Doren, B., GAU, J. M., \& LindSTROM, L. E. (2012). The Relationship between Parent Expectations and Postschool Outcomes of Adolescents with Disabilities. Exceptional Children, 79(1), 7-23. https://doi.org/10.1177/001440291207900101

ERICKSON, K. I., Gildengers, A. G., \& ButTers, M. A. (2013). Physical activity and brain plasticity in late adulthood. Dialogues in clinical neuroscience, 15(1), 99-108.

Foster, S. \& KinuthiA, W. (2003). Deaf Persons of Asian American, Hispanic American, and African American Backgrounds: A study of Intraindividual Diversity and Identity. Journal of Deaf Studies and Deaf Education 8 (3): 271-290.

GAGNÉ, M. \& DECI, E.L. (2005). Self-determination theory and work motivation. Journal of Organizational Behavior, 26: 331-362. doi:10.1002/job.322.

Gregory, S., Bishop, J. And SHELDON, L. (1995). Deaf Young People and Their Families. Cambridge: Cambridge University Press. 
HALPERN, A.S. (1994). Quality of life for students with disabilities in transition from school to adulthood. Soc Indic Res 33, 193-236.

https://doi.org/10.1007/BF01078962

HARMON, M., MANLON, S., \& BEACH, R. (2019). Model Transition Process for Deaf and Hard-of-Hearing Youth. JADARA, 26(1).

Retrieved from https://repository.wcsu.edu/jadara/vol26/iss1/6

JONES, G. \& WALlaCE, C. (1992). Family, Youth and Citizenship, Buckingham: Open University Press.

KOCHHAR-BRYANT, C., BASSETT, D. \& WEBB, K. (2009). Transition to postsecondary education for students with disabilities. Thousand Oaks, CA: Sage/Corwin Press.

MARTIN, J., MARShall, L., \& DePRY, R. (2001). Participatory decision-making: Innovative practices that increase student self-determination. In Flexer, R., Simmons, T., Luft, P., \& Bart, R. (Eds.). Planning transitions across the life span. Columbus, $\mathrm{OH}$ : Prentice Hall/Merrill Education.

McDonnall, M. C. (2010). Factors Predicting Post-High School Employment for Young Adults With Visual Impairments. Rehabilitation Counseling Bulletin, 54(1), 36-45. https://doi.org/10.1177/0034355210373806

MCDONNALL, M. C., \& CRUdDEN, A. (2009). Factors Affecting the Successful Employment of Transition-Age Youths with Visual Impairments. Journal of Visual Impairment E Blindness, 103(6), 329-341. https://doi.org/10.1177/0145482X0910300603

Michael, R., CinAMON, R. G., \& MOST, T. (2015). Career-related parental support of adolescents with hearing loss: Relationships with parents' expectations and occupational status. American Annals of the Deaf, 160(1), 6072 .

MOORHEAD, D. (1995). Knowing who I am, in Gregory, S. (ed.) Deaf Futures Revised. Issues in Deafness, Buckingham: Open University.

MorRow, V. \& RichARDS, M. (1996). The Ethics of Social Research with Children: An Overview1. Children \& Society, 10: 90-105. doi: 10.1111/j.1099-0860.1996.tb00461.x

PARASNIS, I., SAMAR, V.J., \& MANDKE, K. (1996). Deaf Adults' Attitudes Toward Career Choices for Deaf and Hearing People in India. American Annals of the Deaf 141(5), 333-339. doi:10.1353/aad.2012.0239.

RABren, K., DunN, C., \& CHAmbers, D. (2002). Predictors of Post-High School Employment Among Young Adults with Disabilities. Career Development for Exceptional Individuals, 25(1), 25-40. https://doi.org/10.1177/088572880202500103 
ReIFF, H. B., \& Gerber, P. J. (1991). Adults with learning disabilities. In N. N. Singh \& I. L. Beale (Eds.), Current perspectives in learning disabilities: $\mathrm{Na}$ ture, theory, and treatment (pp. 170-198). New York, NY: Springer-Verlag.

RodrigueZ, R. J., \& CAVENDiSH, W. (2013). Differences in the Relationship Between Family Environments and Self-Determination Among Anglo, Latino, and Female Students With Disabilities. Career Development and Transition for Exceptional Individuals, 36(3), 152-162. https://doi.org/10.1177/2165143412461524

SANFord, C., NeWMan, L., WAGner, M., CAMETO, R., KNOKEY, A.-M., \& SHAVER, D. (2011). The PostHigh School Outcomes of Young Adults With Disabilities up to 6 Years After High School. Key Findings From the National Longitudinal Transition Study-2 (NLTS2) (NCSER 2011-3004). Menlo Park, CA: SRI International.

Shogren, K. A., Wehmeyer, M. L., Palmer, S. B., Rifenbark, G. G., \& Little, T. D. (2015). Relationships Between Self-Determination and Postschool Outcomes for Youth With Disabilities. The Journal of Special Education, 48 (4), 256-267. https://doi.org/10.1177/0022466913489733

SimOnSEN, M. L., \& NEUBERT, D. A. (2013). Transitioning Youth With Intellectual and Other Developmental Disabilities: Predicting Community Employment Outcomes. Career Development and Transition for Exceptional Individuals, 36(3), 188-198.

https://doi.org/10.1177/2165143412469399

SOENENS, B. \& VANSTEENKISTE, M. (2005). Antecedents and Outcomes of Self-Determination in 3 Life Domains: The Role of Parents' and Teachers' Autonomy Support. J Youth Adolescence 34, 589-604.

https://doi.org/10.1007/s10964-005-8948-y

Wehman, P., Sima, A.P., Ketchum, J. ET AL. Predictors of Successful Transition from School to Employment for Youth with Disabilities. J Occupational Rehabilitation 25, 323-334 (2015).

https://doi.org/10.1007/s10926-014-9541-6

WehmeYer, M. (1995). The Arc's Self-Determination Scale: Procedural Guidelines. Baltimore, MD: Paul H. Brooks Publishers.

WeHMEYER, M.L. \& GARNER, N.W. (2003). The Impact of Personal Characteristics of People with Intellectual and Developmental Disability on Self-determination and Autonomous Functioning. Journal of Applied Research in Intellectual Disabilities, 16: 255-265.

doi:10.1046/j.1468-3148.2003.00161.x

WeHmeyer, M. (2007). Promoting Self-Determination in Students with Developmental Disabilities. New York: The Guilford Press.

Wehmeyer, H., Abery, D., Zhang, K., Ward, D., Willis, A., Hossain, B., AlliSON, B., BACON, C., CAlKins, T., Heller, T., GOOdE, R., Dias, G., Jesien, T., McVeigh, M., Nygren, S., \& Hill, W. (2011). Personal Self-Determi- 
nation and Moderating Variables that Impact Efforts to Promote SelfDetermination, Exceptionality, 19:1, 19-

30, DOI: $10.1080 / 09362835.2011 .537225$

WONG, M. M. (2008). Perceptions of parental involvement and autonomy support: Their relations with self-regulation, academic performance, substance use and resilience among adolescents. North American Journal of Psychology, 10(3), 497-518.

Valentine, G., \& Skelton, T. (2007). Re-Defining 'Norms': D/Deaf Young People's Transitions to Independence. The Sociological Review, 55(1), 104-123. https://doi.org/10.1111/j.1467-954X.2007.00684.x 